引用格式: 刘佳,刘宁. 湤苔绿潮影响下滨海旅游环境价值损失及影响因素——以青岛市海水浴场为例 [J]. 资源科学, 2018,40 (2) : 392-403. [Liu J, Liu N. Evaluating the environmental value loss of coastal tourism and influencing factors under the influence of Enteromorpha prolifera disasters at the bathing beaches in Qingdao[J]. Resources Science, 2018,40(2):392-403.] DOI :10.18402/ resci.2018.02.15

\title{
浒苔绿潮影响下滨海旅游环境价值损失及影响因素 以青岛市海水浴场为例
}

\author{
刘 佳 ${ }^{1,2}$, 刘 宁 $^{1}$
}

(1. 中国海洋大学管理学院, 青岛 266100;

2. 教育部人文社会科学重点研究基地中国海洋大学海洋发展研究院,青岛 266100)

\begin{abstract}
摘 要: 近年来湤苔绿潮灾害在青岛海域频繁出现。吘苔暴发期间青岛市滨海旅游生态环境和旅游景观受到 侵害, 在一定程度上影响了相关滨海旅游活动的开展。本文采用条件价值法 (CVM), 基于游客对游苔治理支付意 愿 (WTP) 的调查, 定量评估湖苔绿潮影响下青岛市滨海旅游环境价值损失。研究结果表明: 游客对滸苔灾害的认 知程度普遍较低; 愿意支付与拒绝支付费用以治理湃苔的游客比例相当; 游客参与治理汻苔的人均支付意愿值为 40.72 元/年, 湤苔绿潮影响下青岛滨海旅游环境价值损失在 12.12 亿元 21.36 亿元之间, 占 2016 年青岛市旅游总收 入的 $0.8 \%$ 1.5\%; 游客的可支配月收入及游客对湤苔的认知程度直接影响其支付意愿及 WTP 值, 游客对海水浴场 的满意度对游客的支付意愿产生较大影响, 湤苔灾害影响游客进行滨海休闲活动的程度与其 WTP值显著相关。
\end{abstract}

关键词 : 滨海旅游; 损失评估; 条件价值法; 湤苔绿潮; 支付意愿; 青岛市

DOI :10.18402/resci.2018.02.15

\section{1 引言}

绿潮是由海水中某些大型绿藻 (湤苔)在一定 时期内暴发性增殖, 或聚集达到一定水平, 导致的 海洋生态异常现象 ${ }^{[1]} 。 2007$ 年以来, 汻苔绿潮灾害 在中国黄海海域呈现连续性、大规模与常态化暴发 态势, 成为广泛关注的海洋生态问题。根据国家海 洋局发布的《中国海洋环境状况公报》 ${ }^{[2]}$ 显示, 2016 年吘苔绿潮灾害在中国黄海沿岸海域的最大分布 面积为 $57500 \mathrm{~km}^{2}$, 急剧增殖的湤苔绿潮给沿海地区 的水产养殖业、旅游业、居民生活等带来了诸多负 面影响 ${ }^{[3]}$ 。同样, 湤苔绿潮灾害在青岛海域连续性 暴发, 使得海洋生态环境问题频发、滨海空气质量 下降、滨海景观受到破环, 造成了较为严重的海洋 环境灾害和海洋经济损失, 据统计, 2016年青岛市 海水养殖业损失高达 48 亿元, 应急管理投人 1 亿元
左右, 总损失达近 50 亿元 ${ }^{[4]}$ 。值得注意的是, 湤苔绿 潮集中暴发时间正处于青岛市旅游旺季, 沙滩、岩 石等旅游景观被吘苔侵蚀,近岸海域水质、大气环 境受到一定程度的污染, 沙滩娱乐、沙浴、日光浴、 游泳等滨海休闲项目无法正常开展,湤苔附着游 艇、船舶并产生侵蚀,也严重干扰岸钧、滩钧、体育 运动等海上体验项目的开展, 使得海水浴场的正常 服务功能受到影响。

吘苔绿潮在一定程度上影响着青岛旅游整体 环境, 造成旅游形象损害和旅游经济损失。当前, 吘苔灾害的影响研究得到国内外学者的广泛重 视。国外研究内容集中在吘苔暴发的海域范围及 其成因、作用机理 ${ }^{[5,6]}$ 以及在暴发前的预测、防控 ${ }^{[7]}$ 等 方面,并关注吘苔绿潮暴发所引发的次生灾害 ${ }^{[8]}$, 对 海洋生态系统、海洋生物产生严重的影响 ${ }^{[9,10]}$ 。国内 
研究集中在吘苔的暴发原因、形成机制、损失影响 和治理措施等方面, 如李德萍等 ${ }^{[11]}$ 、张林慧等 ${ }^{[12]}$ 分别 研究了沿海海域汻苔大暴发特征及其成因, 吴孟泉 等 ${ }^{[13]} 、$ 矫新明等 ${ }^{[14]}$ 、刘帆等 ${ }^{[15]}$ 均探讨了沿海海域吘苔 时空分布特征及对生态环境产生的影响。同时,有 害藻类对旅游业的损害影响 ${ }^{[16]}$ 也得到初步研究, 如 江天久等 ${ }^{[17]}$ 采用实地调研方法评估赤潮灾害对旅游 观光业直接经济损失; 周罡 ${ }^{[18]}$ 运用现行市价法评估 近海藻华灾害对旅游业的经济损失; 刘佳等 ${ }^{[19]}$ 探讨 了吘苔绿潮灾害对青岛市滨海旅游环境造成损害的 区域范围、旅游产品与行业部门。综上, 汻苔绿潮 灾害对海洋环境、滨海旅游环境以及次生灾害影响 的研究得到肯定, 但有关游苔绿潮对滨海旅游环境 价值损失的定量评估研究稍显不足。

当前有关灾害类事件对旅游损失评估研究成果 较为丰富。国外学者普遍利用定性与定量结合的 方法进行旅游损失评估, 定性分析如小组访谈法 ${ }^{[20]}$ 、 叙事法 ${ }^{[2]}$ 等, 定量评价包括经济评估法 ${ }^{[2]}$ 、SARIMA 模型 ${ }^{[23]}$ 、ARIMA 模型 ${ }^{[24]}$ 等预测模型。在国内, 旅游 经济损害评估模型 ${ }^{[25]}$ 、时间序列分析法 ${ }^{[26]}$ 、相邻年比 较法 ${ }^{[27]}$ 、旅游本底趋势线 ${ }^{[28,29}$ 等方法得到广泛应用、 检验和评估。但既有研究忽视了游客对旅游目的 地遭受损害的感知, 因而对灾害所引发的旅游损失 进行评价会产生一定的偏差。条件价值法 (CVM) 已被广泛应用于环境质量改善和环境价值损失评 估的研究中, 其通过构造假想市场直接询问受访者 对某一环境物品效益改善的最大支付意愿 (Willingness to Pay, WTP), 或者对于环境质量恶化希望获 得的最小补偿意愿 (Willingness to Accept, WTA), 以受访者回答的 WTP 或 WTA 值来估计环境效益 改善或环境质量损失的经济价值 ${ }^{[30]}$, 其已成为生态 经济学和环境经济学领域中衡量非市场物品的重 要方法。Randell 等 ${ }^{[3]}$ 在 1974 年开始将 CVM 应用于 环境质量改善研究, 目前该方法主要运用在矿区开 发 ${ }^{[2-35]}$ 、湿地保护 ${ }^{[36]}$ 、水质改善 ${ }^{[37,38]}$ 等领域生态环境破 坏的价值损失评估研究中, 但在旅游环境损失研究 中, CVM 方法较少得到应用。滨海旅游资源与海域 生态环境是青岛旅游业发展的重要条件和基础, 吘 苔绿潮暴发期间, 青岛滨海旅游环境质量下降, 严 重影响了游客的旅游体验和满意度, 因湤苔绿潮灾
害而造成的滨海旅游环境问题亟需解决。科学评 估湤苔绿潮灾害影响下的滨海旅游环境价值损失, 可为解决滨海旅游环境污染、游惒空间缩减等问题 提供理论指导和决策参考。滨海旅游环境作为一 种公共物品, 湤苔绿潮影响下其旅游环境价值损失 不能通过市场机制反映出来, 需要通过假想市场来 评估。因此,本文运用条件价值法 $(\mathrm{CVM})$, 通过调查 游客对治理湤苔和改善滨海旅游环境的支付意愿 (WTP), 研究湤苔绿潮灾害造成的青岛市滨海旅游 环境价值损失, 以期优化与提升青岛市滨海旅游环 境质量,促进滨海旅游业的可持续发展。

\section{2 研究区概况、数据来源与研究方法}

\section{1 研究区概况}

青岛是全国首批沿海开放城市、优秀旅游城 市, 地处山东半岛南部, 东、南濒临黄海, 海岸线绵 延曲折, 广阔的海域空间、丰富的海岛及海洋生物 资源, 为其滨海旅游业发展提供了良好的基础和条 件。近年来,青岛市滨海旅游业保持平稳、快速的发 展态势, 2016 年接待旅游总人次 8081.1 万人, 实现 旅游总收人 1438.7 亿元, 已成为海洋经济的主导产业 之一 ${ }^{[39]}$ 。与此同时, 《山东省“十三五”海洋经济发展 规划》、《青岛市“十三五”蓝色经济创新发展研究》等 相关文件陆续出台 ${ }^{[40,41]}$, 为优化青岛市滨海旅游环 境与加快滨海旅游业可持续发展提供了政策保障。

海水浴场作为青岛市滨海旅游业发展的重要 载体,也是汻苔灾害影响的主要区域。根据国家海 洋局北海预报中心监测数据显示, 从湤苔空间分布 特征来看,近年来青岛吘苔绿潮主要分布于第一、 二、三、六海水浴场,东海西路西,石老人,流清河等 海域。根据中国海洋环境状况公报显示, 2016年 6 月底湤苔绿潮漂浮至青岛海岸, 7 月初至中旬大规 模暴发,随后青岛海岸绿潮分布面积迅速缩小, 8 月 初绿潮基本消亡。吘苔暴发期间, 青岛海水浴场近 岸海域水质、大气环境及滨海旅游景观均受到侵 害, 沙滩娱乐、海上体验项目等旅游活动开展受到 一定的限制, 游客的旅游体验质量显著下降, 旅游 企业营业利润呈现不同程度的减少。

\section{2 基于 CVM 的问卷调查与数据来源}

\subsection{1 调查问卷设计}

科学合理的问卷设计能有效减少和避免偏 
差 ${ }^{[42]}$ 。为提高研究结果的有效性和可靠性, 本文参 考美国大气与海洋管理局 (NOAA) 提出的 CVM 问 卷设计及调查原则 ${ }^{[43]}$, 同时借鉴国内外有关学者对 旅游损害、生态环境价值损害 CVM 评估等领域的 研究成果 ${ }^{[44-46]}$, 结合滨海旅游环境及吘苔灾害特征, 进行问卷设计。正式调查问卷分为三部分。

第一部分是对游客的社会经济属性调查, 包括 性别、年龄、游客来源、受教育程度、职业、月收人。

第二部分是游客对汻苔的认知情况, 包括游客对 青岛市海水浴场的满意度, 游客到海水浴场的出游次 数、游客对湤苔的认知程度及吘苔灾害对游客滨海观 光旅游、滨海休闲活动、海上娱乐活动等的影响程度。

第三部分是游客对治理汻苔灾害的支付意愿 调查, 该部分为湤苔灾害造成青岛市滨海旅游环境 价值损失评估的核心环节。首先, 通过构建假想市 场, 直接询问游客对治理青岛浒苔灾害、改善滨海 旅游环境的支付意愿, 在此提醒游客并不是真正的 支付, 并根据自己的真实情况进行回答, 以提高其 支付意愿的真实性。其次本文以国外学者 Cummings、Bateman、Turner、Arrow 提出的原则 ${ }^{[47]}$ 为基 础, 借鉴国内有关生态环境价值损害 ${ }^{[29]}$ 、旅游损害 ${ }^{[30]}$ 等领域的实践经验, 采用连续型条件价值评估中支 付卡式设定支付意愿投标值大小, 在此基础上, 通过 预调研方式, 确定支付意愿投标值的范围, 最终确定 调查问卷中 18 个投标值, 分别为 5 元、 10 元、 20 元、 30 元、 40 元、 50 元、 60 元、70 元、80 元、90 元、 100 元、 150 元、200 元、 250 元、300 元、350 元、400 元、>400 元。其中, 支付卡式调查问卷的核心问题如下:

您是否愿意为治理浒苔、保护滨海旅游环境而 支付一定费用呢?

\section{$\square$ 愿意 $\square$ 不愿意}

若愿意, 请选择您愿意支付的金额 (元) (注: 只 用于数据调查并不需要真正支付)

$\square 5 \square 10 \square 20 \square 30 \square 40 \square 50 \square 60 \square 70$
$\square 80 \square 90 \square 100$
$\square 150 \square 200 \square 250 \square 300 \square 350 \square 400$
$\square>400$ 请填写具体金额 $\square$ 元。

2.2.2 数据来源、问卷偏差处理

基于青岛市海水浴场受汻苔绿潮灾害的严重 程度, 选取第一海水浴场、第二海水浴场、第六海水
浴场(栈桥)、石老人海水浴场作为调研区域进行随 机抽样调查。样本大小直接影响实地调研的成本、 时间和可信度, 游客的样本数量可采用 Scheaffer 公 式 ${ }^{[48]}$ 确定, 即:

$$
N=\frac{n}{(n-1) \delta^{2}+1}
$$

式中 $N$ 为抽样本总体; $n$ 选取 2016 年青岛市第三季 度接待游客总量为下限值, 2016 年青岛市第二、三 季度接待游客总量为上限值; $\delta$ 为抽样误差 $(\delta=$ $5 \%$ ）。在本研究中, 2016 年青岛市第三季度接待游 客总量为 2976.1 万人次, 2016 年青岛市第二、三季 度接待游客总量为 5245.9 万人次, 由此可知, 样本 数量 $N$ 至少 400 份视为有效。

2017 年青岛汻苔绿潮灾害暴发时间为 6 月底至 7 月初。本研究于 2017 年 6 月 20 日-22 日开始进 行实地预调研, 以此确定问卷中游客支付意愿值的 取值范围。2 017 年 6 月 23 日-7月 14 日进行正式 调研, 发放问卷共计 550 份, 实地发放问卷 400 份, 网络问卷 150 份,其中实地有效问卷 384 份, 无效问 卷 16 份, 网络有效问卷 143 份, 无效问卷 7 份, 有效 问卷共计 527 份, 有效率 $95.8 \%$ 。根据美国国家海 洋和大气管理局 (NOAA) 建议,面访调查中 $70 \%$ 回 收率比较合理, 而 $75 \%$ 回收率则更有效 ${ }^{[49]}$, 由此可见, 此次调查问卷样本数量及其数据均符合研究标准。

CVM方法中的偏差因素贯穿于问卷设计、问卷 调查、数据分析中, 为减少出现的偏差对评估产生 影响, 在充分了解青岛市海水浴场现状的同时, 结 合国内外提出的偏差处理措施, 对问卷设计、调查 以及处理进行了严格的操作(见表 1)。

\section{3 游客支付意愿及 WTP 值影响因素选取}

基于 CVM 的环境价值损失评估过程是在一定 的地域范围内对受访者进行调查, 分析样本中受访 者的人口特征、社会经济特征或其他相关因素对支 付意愿及 WTP 值的影响研究, 是验证 CVM 有效性 和可靠性的重要手段及关键步骤之一 ${ }^{[50,51]}$ 。在影响因 素的选择中, 国外学者开展了大量的实证研究 ${ }^{[47,52]}$, 同时国内学者也进行了相关验证分析 ${ }^{[33-55]}$ 。已有研 究表明, 支付意愿及 WTP 值影响因素一般包括居民 的人口特征, 如性别、年龄、家庭人口数; 社会经济 状况, 如收人水平、教育程度; 地理区位以及居民的 
表 1 治理湤苔灾害调查偏差类型及处理措施

Table 1 The deviation types and measures of the treatment of Enteromorpha prolifera disasters survey

\begin{tabular}{ll}
\hline \multicolumn{1}{c}{ 偏差类型 } & \multicolumn{1}{c}{ 偏差处理措施 } \\
\hline 假想偏差 & 引导游客认识治理汻苔灾害这一假想市场的真实性,并提醒游客选择的支付意愿值应根据自身的实际收人情况 \\
投标值范围偏差 & 而定 \\
信息偏差 & 告知游客受浒苔绿潮灾害期间,青岛市海水浴场的真实受灾情况 \\
策略性偏差 & 采取匿名填写的方法,并告知游客支付意愿值对结果评估有很大影响 \\
抗议性偏差 & 利用问卷中 “愿值,根据预调研界定拒绝为治理淔范围 \\
& 中苔而支付一定费用,其原因是?”这一问题来明确拒绝支付的原因,并在数据分析 \\
调查停留时间偏差 & 问卷设计简单易懂,便于游客填写 \\
\hline
\end{tabular}

环境认知态度等方面。因此,本文借鉴已有研究成 果, 结合游客特征与湤苔灾害的影响程度,主要选 取以下影响因素：

(1)游客的人口特征因素。其中, 性别 $(S E X)$ 用 以反映性别差异对支付意愿及 WTP值的影响;年龄 $(A G E)$ 用以反映年龄、社会经验对支付意愿及 WTP 值的影响; 职业 $(J O B)$ 用以反映工作性质对支付意 愿及 WTP 值的影响。

(2)游客的社会经济特征因素。其中, 受教育 程度 $(E D U)$ 用以反映学习能力与文化水平对支付 意愿及 WTP 值的影响; 月收人 $(I N C)$ 用以反映收人 水平对支付意愿及 WTP值的影响; 到海水浴场的出 游次数 (FREQ) 用以反映游客到海水浴场进行观光 体验的旅游次数对支付意愿及 WTP 值的影响。

(3)游客的环境认知程度因素。其中, 对海水 浴场的满意度 $(S A T I S F Y)$, 反映游客对海水浴场风 景满意程度对支付意愿及 WTP 值的影响; 对许苔的 认知程度 (FAMI), 反映游客对汻苔了解程度对支付 意愿及 WTP 值的影响; 浒苔对游客的滨海观光旅游 影响程度 (INFLU1)、对游客的滨海休闲活动的影响 程度 (INFLU2)、对游客的海上娱乐活动的影响程度 (INFLU3) 可反映吘苔灾害干扰游客进行滨海旅游 活动的程度对支付意愿及 WTP 值的影响, 以进一步 验证既有研究中提出的研究假设 ${ }^{[19]}$ 。

\section{3 结果及分析}

\section{1 样本特征分析}

在 527 份有效问卷中, 男性游客占 $47.8 \%$, 女性 游客占 52.2\%, 男女比例基本相当; 年龄以 18 25 岁 的比例最高, 占 $38.0 \%$, 其次 26 30 岁、31 40 岁年龄 段的游客居多,分别占 $20.5 \% 、 23.5 \%$; 来自山东省内
的游客居多, 占 $57.5 \%$, 其中, 青岛市本地游客占 $28.5 \%$, 其次是来自山东省外的国内游客, 占 $41.2 \%$; 游客受教育程度普遍较高, 其中本科学历占 $38.1 \%$, 大专学历占 $22.2 \%$, 硕士及以上学历占 $15.7 \%$; 三者 合计共占 $76.0 \%$, 可见游客普遍对调查问卷有较强 的理解力; 参与调查的游客月收人普遍较低, 游客 可支配收人以 1000 元以下为主, 其次是 2001 3000 元、 $4001 \sim 6000$ 元,均占 $15.4 \%$; 由于调研时间段为学 校暑假期间, 游客中学生、教师比例较高, 分别占 $28.1 \% 、 26.6 \%$; 问卷样本中调查显示, 游客对青岛市 海水浴场的风景基本满意, 到海水浴场的出游次数 多为 $0 \sim 1$ 次, 占总体样本的 $44.2 \%$, 游客的出游动机 大多为放松心情、娱乐度假。综上所述, 本调查样 本设计范围较为全面, 具有典型性特征, 能够客观 反映青岛游客总体样本特征。

\section{2 游客对湤苔的认知程度}

根据调查结果可知,游客对湤苔的认知程度较 低, $46.5 \%$ 对湤苔不了解, $29.4 \%$ 了解吘苔是一种有 害藻类, 但更进一步的了解较少。游客对吘苔灾害 暴发产生滨海旅游环境影响的感知体现在: 浒苔严 重干扰滨海观光旅游、影响滨海休闲与娱乐活动, 具体表现为以下三点。(1)破坏滨海旅游景观,干扰 滨海旅游观光活动。大量湤苔长时间堆积后腐败 变质, 影响近岸海域的水质及海岸景观, 使得滨海 景观遭受污染,滨海景观的完整性遭到破坏,降低 了游客滨海旅游体验质量和满意度。(2)扰滨海 休闲活动。吘苔的大量繁殖影响了滨海休闲活动 的开展,使沙滩排球、沙滩宿营、沙滩拔河等沙滩娱 乐项目,游泳、沙浴、日光浴等沙滩休闲项目以及岸 钓、滩钓无法正常开展。(3)限制海上娱乐活动。湤 
苔常附着在游艇、船只的表面, 使得冲浪、滑板、摩 托艇、水上单车、帆船运动、海上游钓等海上娱乐项 目无法正常开展,船钓、人工渔礁、休闲垂钓等水上 体验活动也受到一定影响。

\section{3 游客支付意愿及 WTP 值统计}

问卷中涉及是否愿意为治理汻苔灾害而支付 一定的费用等问题, 愿意支付的游客占 $50.5 \%$, 不愿 意支付的游客占 $49.5 \%$, 两方支付意愿比例相当。 其中, 愿意为治理湤苔灾害而支付一定费用的游客 是出于保护滨海旅游资源的动机, 而拒绝支付的游 客中, $45.0 \%$ 认为治理汻苔应由政府和旅游企业承 担, $19.3 \%$ 认为支付费用最后无法用在治理湤苔上， $16.2 \%$ 的游客则是由于个人经济的原因,可支配收人 水平高才会为治理汻苔而支付费用。另外, 在调查治 理汻苔的责任方时, $46.0 \%$ 游客认为, 治理吘苔灾害 应由政府负责, 其次 $26.4 \%$ 认为污染水质的相关企业 也应负相应责任, 可见游客虽对治理汻苔的意愿不 一,但在对治理汻苔的责任方的认知方面较为一致。

由统计结果 (图 1) 可以看出, 在愿意支付一定 费用用于治理汻苔的样本中, 最大支付意愿值超过 400 元, 最小支付意愿值为 5 元, 从支付意愿 (WTP) 投标值占比来看, 以每年支付 100 元的人数最多 $(23.7 \%)$, 其次为 10 元的人数 $(18.0 \%)$ 。总体来看, 投标值集中在 10 元、 20 元、 50 元、 100 元这 4 个数值 之间, 且随着投标值的增大, 游客愿意支付费用的频
数呈下降趋势, 这与公众日常的支付心理相一致, 即 金额低的支付频数相对较高, 比较符合实际情况。 由于本研究中支付频数分布较为集中,所以采用受访 游客支付意愿的平均值较为合理,计算公式如下:

$$
E(W T P)_{\text {正 }}=\sum_{i=1}^{m} X_{i} W_{i}
$$

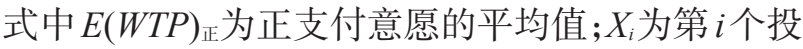
标值; $W_{i}$ 为游客选择第 $i$ 个投标值的频数; $m$ 为投标 值个数,本文中 $m=18$; 通过公式 (2)计算可知, 青岛

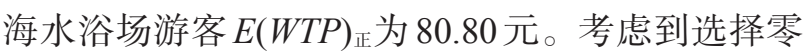
支付意愿的受访游客的真实 $W T P$ 并不一定为零, 所 以进一步采用 Kristrom 的 spike 模型 ${ }^{[56]}$ 对 $E(W T P)_{\text {正 }}$ 进行修正,其公式为:

$$
E(W T P)=E(W T P)_{\text {正 }} \times \text { 支付意愿率 }
$$

式中 $E(W T P)$ 为人均 $\mathrm{WTP}$ 值, 反映的是游客为治理 吘苔绿潮灾害每人每年的平均支付意愿。根据调 查结果, 愿意支付治理㴾苔费用的游客数量为 266 人, 支付意愿率为 $50.4 \%$, 因此, 青岛市游客为治理 湤苔绿潮灾害的 $E(W T P)$ 为 40.72 元/年。

\section{4 湤苔绿潮灾害对滨海旅游环境造成的价值损} 失评估

采用条件价值法 $(\mathrm{CVM})$, 结合游客支付意愿调 查结果, 将湤苔绿潮灾害对青岛市滨海旅游环境造 成的损失进行定量评估。CVM以消费者效用恒定 的福利经济学理论为基础, 在假想市场中, 询问受

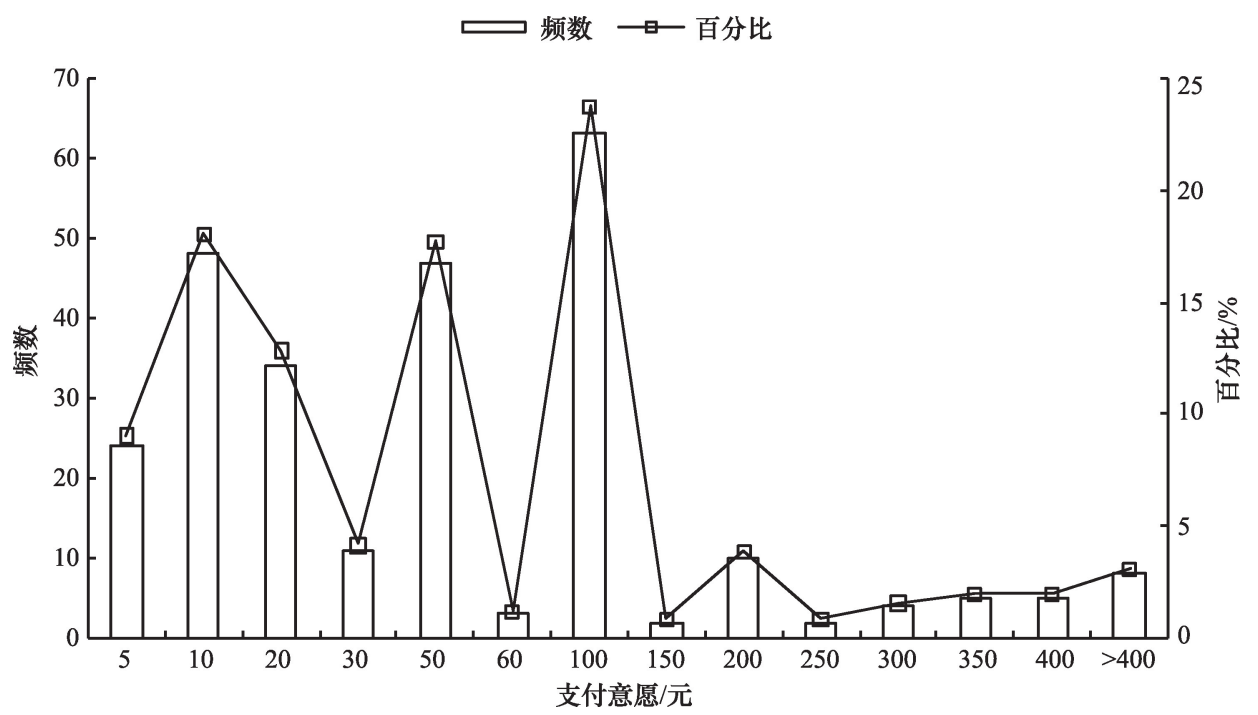

图 1 游客参与治理湤苔灾害的 WTP 值分布

Figure 1 The distribution of WTP values for tourists to participate in the treatment of Enteromorpha prolifera disasters 
访者为使环境质量得到改善而愿意支付的费用,或 者为弥补环境恶化造成的损失而愿意予以补偿的 费用,受访者对 WTP 或 WTA 的选择是个人追求效 用最大化的结果 ${ }^{[57]}$ 。目前在该领域的研究中, 一般 运用受访者的平均支付意愿和调查相关区域的居 民户数量或人口数的乘积来求得生态环境破坏的 总价值损失 ${ }^{[58-60]}$ 。因此, 本文以游客愿意为治理湤 苔的人均 WTP 值乘以青岛市国内外游客总量, 可得 到青岛市每年因湤苔绿潮灾害造成的滨海旅游环 境价值损失。由于青岛市湤苔绿潮灾害通常在每 年 7 月大规模暴发, 本文选取 2016 年青岛市第三季 度接待国内外游客总量作为下限值,2016年青岛市 第二、三季度接待国内外游客总量作为上限值, 从 而计算得到湤苔灾害影响下青岛市滨海旅游环境 价值损失在 12.12 亿元 21.36 亿元之间, 占 2016 年 青岛市旅游总收人的 $0.8 \% \sim 1.5 \%$ 。

\section{5 游客治理湤苔的支付意愿及 WTP 值影响因素 分析}

游客的支付意愿及 WTP 值, 表征游客为治理汻 苔、保护滨海旅游环境的支付态度及支付水平, 通 过询问游客的支付态度, 即是否愿意支付, 进而确 定愿意支付者的支付水平。本文选取游客的人口特 征、社会经济特征、环境认知程度等影响因素作为自 变量。首先运用二元 Logistic 回归模型, 以游客的 支付意愿为因变量, 对游客的支付意愿影响因素进
行分析; 其次,运用线性回归模型, 以游客的 18 个 WTP 投标值为因变量, 对游客WTP值大小影响因素 进行分析。分析前对自变量进行赋值说明（见表2）。

二元 Logistic 回归模型结果可知 (见表 3 ), 变量 SATISFY 在 0.01 水平上显著且回归系数为负, 表现 为游客对海水浴场的满意程度越低,治理浒苔灾害 的支付意愿越强, 说明游客对海水浴场的满意度是 影响游客支付意愿的主要因素。分析其深层原因, 随着中国高度重视滨海旅游业的发展, 游客的生态 环境意识和关注度也不断提高, 湤苔绿潮灾害破坏 了滨海旅游环境, 在一定程度上影响了游客正常旅 游活动的展开。对海水浴场的满意度可以体现游 客对政府部门及相关旅游企业的满意程度,进而反 映中国在旅游灾害事件发展过程中应急预案的实 施效果, 即游客对海水浴场满意程度越低, 对中国 政府部门及旅游企业防治灾害的管理措施满意度 越低, 面对生态环境待修复的状态, 游客的生态环 境保护意识强烈, 愿意支付更多的 WTP值以治理吘 苔灾害,保护滨海旅游环境。变量 $I N C$ 和 $F A M I$ 在 0.05 水平上显著且回归系数为正, 表明游客可支配 收人、游客对湤苔的认知程度对游客支付意愿产生 正向显著影响, 表现为游客个人月收人越高, 支付 意愿越高, 而且游客对湤苔的了解程度越深, 其支 付意愿越高, 说明游客支付水平与对湤苔的认知程 度是影响游客支付意愿的重要因素。其他变量均

表 2 自变量选取及赋值情况

Table 2 Variables and their assignment

\begin{tabular}{|c|c|c|}
\hline 变量符号 & 变量名称 & 变量含义及赋值 \\
\hline SEX & 性别 & 男 $=1$;女 $=2$ \\
\hline$A G E$ & 年龄/岁 & $\leqslant 18=1 ; 18 \sim 25=2 ; 26 \sim 30=3 ; 31 \sim 40=4 ; 41 \sim 50=5 ; 51 \sim 60=6 ; \geqslant 61=7$ \\
\hline$J O B$ & 职业 & $\begin{array}{l}\text { 学生 }=1 \text {; 教师 }=2 \text {; 公务员 }=3 \text {; 事业单位工作人员 }=4 \text {; 企业中高层管理者 }=5 \text {; 医务 } \\
\text { 工作者 }=6 \text {; 个体工商经营者 }=7 \text {; 自由职业者 }=8 \text {; 退休人员 }=9 \text {; 其他 }=10\end{array}$ \\
\hline$E D U$ & 受教育程度 & $\begin{array}{l}\text { 小学以下 }=1 \text {; 初中及以下 }=2 \text {; 高中或中专 }=3 \text {; 大专 }=4 \text {; 本科 }=5 \text {; 硕士 }=6 \text {; 博士及 } \\
\text { 以上 }=7\end{array}$ \\
\hline$I N C$ & 月收人/元 & $\begin{array}{l}\leqslant 1000=1 ; 1001 \sim 2000=2 ; 2001 \sim 3000=3 ; 3001 \sim 4000=4 ; 4001 \sim 6000=5 ; \\
6001 \sim 8000=6 ; 8001 \sim 10000=7 ; \geqslant 10001=8\end{array}$ \\
\hline FREQ & 到青岛市海水浴场的出游次数/次 & $0 \sim 1=1 ; 2 \sim 3=2 ; 4 \sim 5=3 ; \geqslant 6=4$ \\
\hline SATISFY & 对青岛市海水浴场的满意度 & 非常不满意 $=1$; 不满意 $=2$;一般 $=3$; 满意 $=4$; 非常满意 $=5$ \\
\hline FAMI & 对浒苔的认知程度 & 自然生长的草本植被 $=1$;有害藻类=2;不了解=3 \\
\hline$I N F L U 1$ & 吘苔对游客的滨海观光旅游的影响程度 & 一点不影响 $=1$; 不影响 $=2$; 一般 $=3$; 影响 $=4$; 非常影响 $=5$ \\
\hline INFLU2 & 湤苔对游客的滨海休闲活动的影响程度 & 一点不影响 $=1$; 不影响 $=2 ;$ 一般 $=3$; 影响 $=4$; 非常影响 $=5$ \\
\hline INFLU3 & 湤苔对游客的海上娱乐活动的影响程度 & 一点不影响 $=1$; 不影响 $=2 ;$ 一般 $=3$; 影响 $=4$; 非常影响 $=5$ \\
\hline
\end{tabular}


表 3 游客治理湤苔灾害的支付意愿及WTP值影响因素回归分析结果

Table 3 The results of regression analysis of the influencing factors of the willingness to pay and WTP values of tourists for the treatment of Entermorpha prolifera disasters

\begin{tabular}{|c|c|c|c|c|c|c|c|c|}
\hline \multirow{2}{*}{ 变量 } & \multicolumn{4}{|c|}{ 二元Logistic 回归分析结果 } & \multicolumn{4}{|c|}{ 线性回归分析结果 } \\
\hline & 回归系数 & 标准误差 & Wals & 显著性水平 & 回归系数 & 标准误差 & $t$ 检验 & 显著性水平 \\
\hline$S E X$ & -0.172 & 0.192 & 0.801 & 0.371 & -1.332 & 0.642 & -2.169 & $0.032 * *$ \\
\hline$A G E$ & 0.018 & 0.077 & 0.052 & 0.320 & 0.010 & 0.250 & 0.040 & 0.168 \\
\hline$E D U$ & -0.058 & 0.081 & 0.501 & 0.479 & 0.410 & 0.283 & 1.447 & 0.149 \\
\hline$J O B$ & 0.031 & 0.038 & 0.666 & 0.414 & 0.104 & 0.137 & 0.759 & 0.449 \\
\hline$I N C$ & 0.088 & 0.052 & 2.870 & $0.050 * *$ & 0.360 & 0.177 & 2.030 & $0.043^{* *}$ \\
\hline FREQ & 0.051 & 0.093 & 0.305 & 0.581 & 0.607 & 0.277 & 2.190 & $0.029 * *$ \\
\hline SATISFY & -0.239 & 0.089 & 7.198 & $0.000 * * *$ & 0.223 & 0.294 & 0.759 & 0.449 \\
\hline FAMI & 0.219 & 0.114 & 3.682 & $0.045^{* *}$ & -0.881 & 0.360 & -2.448 & $0.015^{* *}$ \\
\hline$I N F L U 1$ & -0.113 & 0.129 & 0.773 & 0.379 & 0.014 & 0.416 & 0.032 & 0.374 \\
\hline$I N F L U 2$ & 0.133 & 0.149 & 0.799 & 0.371 & 1.360 & 0.487 & 2.793 & $0.000 * * *$ \\
\hline INFLU3 & -0.143 & 0.134 & 1.136 & 0.287 & 0.191 & 0.431 & 0.442 & 0.259 \\
\hline
\end{tabular}

注: ***、**分别表示在 $1 \% 、 5 \%$ 的统计检验水平上显著。

未对游客的支付意愿产生显著影响。

在游客愿意支付的基础上,运用线性回归模型 对游客WTP值影响因素进行分析 (见表 3), 变量 $I N-$ $F L U 2$ 在 0.01 水平上对游客 WTP值产生显著影响且 回归系数绝对值最大, 表现为游客认为吘苔灾害对 游客滨海娱乐活动影响程度越深, 游客愿意为治理 游苔、保护滨海旅游环境的 WTP 值越大, 说明吘苔 绿潮灾害对滨海娱乐活动影响程度为游客 WTP 值 的主要影响因素。吘苔绿潮灾害已破坏滨海旅游 环境, 妨碍游客滨海旅游活动的正常开展, 政府部 门及旅游企业应予以高度重视, 提出防治汻苔绿潮 灾害的有效措施。变量 $S E X$ 在 0.05 水平上显著且 回归系数为负, 表明性别不同对治理汻苔的支付意 愿有所差异, 相对于女性而言, 男性更愿意较高费 用来治理浒苔灾害, 究其原因是由于男性在保护环 境意识中更具有社会责任感, 愿意支付一定费用改 善生态环境。变量 $F R E Q$ 在 0.05 水平上显著且回归 系数为正, 表明游客的出游次数对 WTP 值产生显著 影响, 表现为青岛市海水浴场观光体验的次数越 多, 对滨海风景产生了一定的情感依赖性, 愿意治 理许苔灾害的 WTP 值越高。变量 $I N C$ 和 FAMI 在 0.05 水平上显著且回归系数为正, 表现为游客个人 可支配收人、游客对湤苔的认知程度对游客 WTP 值 产生正向显著影响, 说明游客支付水平与对湤苔的 认知程度是影响游客 WTP值的重要因素。其他变
量均未对游客的支付意愿产生显著影响。

值得注意的是, 二元 Logistic 回归模型和线性 回归模型结果均表明 (见表 3 ), 游客支付水平与对 浒苔的认知程度是影响支付意愿及 WTP 值的重要 因素, 支付水平较高或对吘苔认知程度较深的游客 支付意愿越强烈, WTP 值越大。究其原因,一方面, 随着国民收人水平的提高,游客对休闲娱乐、康养、旅 游等精神需求大大提高, 对生态环境、旅游景观有 更高的质量要求, 因此游客对治理湤苔灾害、保护 滨海旅游环境的支付意愿及 WTP 值也会有明显的 提升。另一方面, 游客对许苔的认知程度也是较为重 要的因素, 游苔绿潮作为一种有害藻类, 对滨海旅 游和城市形象造成一定负面影响,势必会损害游客 进行滨海观光、滨海娱乐、海上体验等滨海旅游活 动, 游客越了解汻苔的危害, 越能理解治理汻苔灾害 的重要性,进一步提升海洋生态环境的保护意识, 为治理湤苔的支付意愿更加强烈, 且 WTP 值较高。

\section{4 结论与讨论}

\section{1 结论}

本研究采用实地调研的方式实证检验与定量 评估湤苔绿潮影响下青岛市滨海旅游环境价值损 失。湤苔作为一种有害藻类, 其周期性、大规模的 暴发对青岛市海水浴场的景观、游客的滨海观光旅 游、滨海休闲活动、海上娱乐活动产生了较大的影 响和损害。本文利用条件价值法 (CVM), 定量评估 
了湤苔绿潮灾害对青岛市滨海旅游环境造成的损 失, 并运用二元 Logistic 回归模型及线性回归模型 对游客的支付意愿及 WTP 值影响因素进行分析, 得 出以下结论:

(1) 在调查样本中, 愿意为治理湤苔而支付一 定费用的游客占 $50.5 \%$, 不愿意支付的游客占 $49.5 \%$, 两方支付意愿比例相当。愿意支付的动机 多为保护滨海旅游资源, 拒绝支付的原因是游客认 为治理汻苔应由政府和旅游企业承担主要责任。

(2) 青岛市海水浴场游客愿意治理湤苔的 $E$

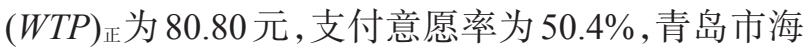
水浴场游客愿意治理湤苔的 $E(W T P)$ 为 40.72 元/年, 吘苔绿潮灾害造成的青岛滨海旅游环境价值损失 在 12.12 亿元 21.36 亿元之间, 占 2016 年青岛市旅 游总收人的 $0.8 \% \sim 1.5 \%$ 。

(3)本文对游客的支付意愿及WTP值的影响因 素进行了深人分析, 研究表明, 游客的可支配收人 及其对吘苔的认知程度直接影响其支付意愿及 WTP值, 游客对海水浴场的满意度对游客的支付意 愿产生较大影响, 湤苔灾害影响游客进行滨海休闲 活动的程度与其 WTP 值显著相关。

\section{2 讨论}

本文运用 $\mathrm{CVM}$, 基于询问游客对湤苔治理的支 付意愿调查, 评估湤苔绿潮灾害对青岛市滨海旅游 环境造成的损失, 由于 CVM 中假想市场的特殊性, 因此损失评估结果与实际有一定的偏差, 在今后研 究中将结合多种评价方法检验和修正湤苔绿潮灾 害对滨海旅游环境价值造成的损失, 降低 CVM 造 成的偏差, 使评估结果更加接近真实值。其次, 本 文测度湤苔绿潮灾害对滨海旅游环境的损害评估 结果是一个动态数据, 随着大众环保意识的增强, 政府监管治理力度的增大, 游客对治理湤苔灾害的 支付意愿也可能会随之改变。因此,政府应加强宣传 和制定滨海旅游环境保护的相关政策,增强游客保护 滨海旅游环境的意识, 提高参与改善滨海旅游环境 的积极性,促进青岛市滨海旅游环境质量的提升。 另外,因受客观条件的限制, 本文基于吘苔灾害对 滨海旅游环境的损害程度,选择以湤苔集中暴发区 域海水浴场为代表, 调查范围有一定的局限性, 相 比于吘苔灾害对整个沿海地区滨海旅游环境造成的
损失, 评估结果可能存在一定的偏差, 需要持续深 人研究、实证检验和修正偏差, 当然对于运用 CVM 评估吘苔绿潮灾害的损失研究值得学术界关注。

\section{参考文献(References):}

[1] 吉启轩, 赵新伟, 章志. 江苏海域湤苔时空分布特征及对海洋环 境的影响[J]. 山东农业大学学报(自然科学版), 2015, (1): 6164. [Gi Q X, Zhao X W, Zhang Z. Spatial and temporal distribution characteristic of the Enteromorpha prolifera in the Jiangsu coastal area and their influence on the ecological environment[J]. Journal of Shandong Agricultural University (Natural Science Edition), 2015, (1): 61-64. ]

[2] 国家海洋局. 2016 年中国海洋环境状况公报[EB/OL]. (201712-04) [2017-12-30]. http: //www.soa.gov.cn/zwgk/hygb/zghyhjzlgb/201712/t20171204_59423.html. [State Oceanic Administration, People's Republic of China. Bulletin of the State of China's Marine Environment in 2016[EB/OL]. (2017-12-04) [2017-12-30]. http: //www.soa.gov.cn/zwgk/hygb/zghyhjzlgb/201712/t20171204_ 59423.html. ]

[3] 罗民波, 刘峰. 南黄海吘苔绿潮的发生过程及关键要素研究进 展 [J]. 海洋渔业, 2015, 37(6): 570-574. [Luo M B, Liu F. Research progress in the key process and main factors of occurrence and development of green tide (Ulva prolifera) in the South Yellow Sea[J]. Marine Fisheries, 2015, 37(6): 570-574. ]

[4] 鄂梦遥, 任俊峰. 防治湤苔要提前跨省联动[EB/OL]. (2017-0417) [2017- 12- 30]. http: //www.dzwww.com/shandong/sdnews/ 201704/t20170417_15788536.htm. [E Meng Y, Ren J F. Provinces United Conduct the Prevention and Control of Enteromorpha in Advance[EB/OL]. (2017-04-17)[2017-12-30]. http: //www.dzwww.com/shandong/sdnews/201704/t20170417_15788536.htm. ]

[5] Keesing J K, liu D, Shi Y, et al. Abiotic factors influencing biomass accumulation of green tide causing Ulva spp. on Pyropia culture rafts in the Yellow Sea, China[J]. Marine Pollution Bulletin, 2016, 105(1): 88-97.

[6] Keesing J K, Liu D, Fearns P, et al. Inter- and intra-annual patterns of Ulva prolifera green tides in the Yellow Sea during 20072009 , their origin and relationship to the expansion of coastal seaweed aquaculture in China[J]. Marine Pollution Bulletin, 2011, 62 (6): 1169-1182.

[ 7] Diaz M, Darnhofer I, Darrot C, et al. Green tides in Brittany: wha can we learn about niche-regime interactions? [J]. Environmental Innovation and Societal Transitions, 2013, 8: 62-75.

[8] Hiraoka M, Ohno M, Kawaguchi S, et al. Crossing test among floating Ulva thalli forming 'green tide' in Japan [J]. Hydrobiologia, 2004, 512(1): 239-245. 
[9] Liu F, Pang S J, Zhao X B, et al. Quantitative, molecular and growth analyses of Ulva, microscopic propagules in the coastal sediment of Jiangsu province where green tides initially occurred[J]. Marine Environmental Research, 2012, 74(3): 56-63.

[10] Fletcher R L. The Occurrence of “Green Tides" - a Review[M]. Berlin: Marine Benthic Vegetation Springer, 1996.

[11] 李德萍, 马艳, 董海鹰, 等. 日照和降水对青岛近海海域汻苔影 响的分析[J]. 海岸工程, 2013, 32(1): 51-59. [Li D P, Ma Y, Dong $\mathrm{H} \mathrm{Y}$, et al. Impact of sunshine duration and precipitation on Enteromorpha prolifera in Qingdao coastal waters[J]. Coastal Engineering, 2013, 32(1): 51-59. ]

[12] 张林慧, 张建恒, 赵升, 等. 2014 年青岛海域消亡漂浮湤苔生理 特征研究 [J]. 上海海洋大学学报, 2016, 25(4): 591-598. [Zhang L H, Zhang J H, Zhao S, et al. Physiological characteristics of the floating Ulva macroalgae along Qingdao coast in 2014[J], Journal of Shanghai Ocean University, 2016, 25(4): 591-598. ]

[13] 吴孟泉, 郭浩, 张安定, 等. 2008 年-2012 年山东半岛海域湤苔 时空分布特征研究 [J]. 光谱学与光谱分析, 2014, 34(5): 13121318. [Wu M Q, Guo H, Zhang A D, et al. Research on the characteristics of Ulva prolifera in Shandong peninsula during 20082012 based on MODIS data[J]. Spectorscopy and Spectral Analysis, 2014, 34(5): 1312-1318. ]

[14] 矫新明, 袁广旺, 毛成责, 等. 2015 年南黄海海域浒苔时空分布 特征[J]. 杭州师范大学学报(自然科学版), 2017, 16(1): 51-56. [Jiao M X, Yuan G W, Mao C Z, et al. Tempo-spatial distribution features of Ulva prolifera in South Yellow Sea in 2015[J]. Journal of Hangzhou Normal University(Natural Science Edition), 2017, 16 (1): 51-56. ]

[15] 刘帆, 费鲜芸, 王旻烨, 等. 黄、东海海域汻苔时空分布变化特征 研究[J]. 海洋环境科学, 2017, 36(3): 416-421. [Liu F, Fei X Y, Wang M Y, et al. Research on the characteristics of Ulva prolifera in Yellow Sea and East Sea[J]. Marine Environmental Science, 2017, 36(3): 416-421. ]

[16] 齐衍萍, 郭莉莉, 尹维翰, 等. 黄海浒苔绿潮防控对策研究 $[J]$. 海 洋开发与管理, 2016, 33(8): 90-92. [Qi Y P, Guo L L, Yin W H, et al. Green tide (Ulva prolifera) prevention and control countermeasures in the Yellow Sea[J]. Ocean Development and Management, 2016, 33(8): 90-92. ]

[17] 江天久, 李支薇, 江涛, 等. 有害赤潮对近岸捕捞及观光旅游业 直接灾害经济损失评估[J]. 水产学报, 2011, 35(10): 15821588. [Jiang T J, Li Z W, Jiang T, et al. Assessment of direct economic loss of inshore fishing and tourism caused by harmful algal blooms[J]. Journal of Fisheries of China, 2011, 35(10): 15821588.]

[18] 周罡. 近海藻华灾害对渔业直接经济损失评估方法研究[J]. 中 国渔业经济, 2015, 33(5): 107-112. [Zhou G. Evaluation methods of direct losses to fisheries by offshore harmful algal blooms disas-
ter[J]. Chinese Fisheries Economics, 2015, 33(5): 107-112. ]

[19] 刘佳, 张洪香, 张俊飞, 等. 浒苔绿潮灾害对青岛滨海旅游业影 响研究[J]. 海洋湖沼通报, 2017, (3): 130-135. [Liu J, Zhang H $\mathrm{X}$, Zhang J F, et al. Study on the effect of green tide disaster in Qingdao coastal tourism[J]. Transactions of Oceanology and Limnology, 2017, (3): 130-135. ]

[20] Okumus F, Altinay M, Arasli H. The impact of Turkey's economic crisis of February 2001 on the tourism industry in Northern Cyprus [J]. Tourism Management, 2005, 26(1): 95-104.

[21] Goodrich J N. September 11, 2001 attack on America: a record of the immediate impacts and reactions in the USA travel and tourism industry[J]. Tourism Management, 2002, 23(6): 573-580.

[22] Mazzocchi M, Montini A. Earthquake effects on tourism in central Italy[J]. Annals of Tourism Research, 2001, 28(4): 1031-1046.

[23] Huang J H, Min J C H. Earthquake devastation and recovery in tourism: the Taiwan case[J]. Tourism Management, 2002, 23(2): $145-154$.

[24] Prideaux B, Laws E, Faulkner B, et al. Events in Indonesia: exploring the limits to formal tourism trends forecasting methods in complex crisis situations [J]. Tourism Management, 2007, 24(4): 475487.

[25] 张广海, 高乐华. 旅游经济损害评估研究初探[J]. 北京第二外国 语学院学报, 2009, 31(1): 16-21. [Zhang G H, Gao L H. Research on tourism economy damage assessment[J]. Journal Beijing International Studies University, 2009, 31(1): 16-21.]

[26] 朱迎波, 葛全胜, 魏小安, 等. SARS 对中国人境旅游人数影响的 研究[J]. 地理研究, 2003, 22(5): 551-559. [Zhu Y B, Ge Q S, Wei X A, et al. Post evaluation of SARS in 2003 to domestic tourism in China-loss estimation in 31 provinces based on background trend line[J]. Economic Geography, 2003, 22(5): 551-559. ]

[27] 魏小安, 曾博伟. 汶川地震后中国旅游形势分析与判断[J]. 旅游 学刊, 2008, 23(8): 13-18. [Wei X A, Zeng B W. An analysis and judgement of China's tourism industry after Wenchuan earthquake [J]. Tourism Tribune, 2008, 23(8): 13-18. ]

[28] 马丽君, 孙根年, 王宏丹, 等. 汶川地震对四川及周边省区旅游 业的影响 $[\mathrm{J}$. 中国人口·资源与环境, 2010, 20(3): 168-174. [Ma L J, Sun G N, Wang H D, et al. Impact of Wenchuan earthquake to tourism of Sichuan and Its neighboring provinces based on natural trend curve[J]. China Population, Resources and Environment, 2010, 20(3): 168-174. ]

[28] 马丽君, 孙根年, 马耀峰, 等. 极端天气气候事件对旅游业的影 响 - 以 2008 年雪灾为例 [J]. 资源科学, 2010, 32(1): 107-112. [Ma L J, Sun G N, Ma Y F, et al. A study on the influence of extreme weather rand climate on tourism: a case on snowstorm in 2008[J]. Resources Science, 2010, 32(1): 107-112. ]

[30] 陈琳, 欧阳志云, 王效科, 等. 条件价值评估法在非市场价值评 估中的应用[J]. 生态学报, 2006, 26(2): 610-619. [Chen L, Ouy- 
ang Z Y, Wang X K, et al. Applications of contingent valuation method in evaluation of non- market values[J]. Acta Ecologica Sinica, 2006, 26(2): 610-619. ]

[31] Randall A, Ives B, Eastman C. Bidding games for valuation of aesthetic environmental improvements [J]. Journal of Environmental Economics \& Management, 1974, 1(2): 132-149.

[32] Rowe R D, Schulze W D, Hurd B, Orr D. Economic Assessment of Damage Related to the Eagle Mine facility[R]. Prepare by Energy and Resource Consultants for Engineering-Science, Inc., Boulder, CO, 1985 .

[33] Damigos D, Kaliampakos D. Assessing the benefits of reclaiming urban quarries: a CVM analysis [J]. Landscape \& Urban Planning, 2003, 64(4): 249-258.

[34] 刘治国, 李国平. 陕北地区非再生能源资源开发的环境破坏损 失价值评估[J]. 统计研究, 2006, 23(3): 61-66. [Liu Z G, Li G P. Environmental damage assessment of non renewable energy resources development in Northern Shaanxi Province[J]. Statistical Research, 2006, 23(3): 61-66. ]

[35] 李国平, 郭江. 基于 CVM 的榆林煤炭矿区生态环境破坏价值损 失研究-以神木县、府谷县和榆阳区为调研区域 $[J]$. 干早区资 源与环境, 2012, 26(3): 17-22. [Li G P, Guo J. The loss of ecological environment damage in Yulin coal mining area due to resource development-taking Shenmu, Fugu, and Yuyang as the investigation regions[J]. Journal of Arid Land Resources and Environment, 2012, 26(3): 17-22. ]

[36] 赵斐斐, 陈东景, 徐敏, 等. 基于 CVM 的潮滩湿地生态补偿意愿 研究-以连云港海滨新区为例[J]. 海洋环境科学, 2011, 30(6): 872-876. [Zhao F F, Chen D J, Xu M, et al. Research of tidal wetland ecological compensation based on CVM-Lianyungang Beach New Area[J]. Marine Environmental Science, 2011, 30(6): 872876. ]

[37] Choe K A, Whittington D, Lauria D T. The economic benefits of surface water quality improvements in developing countries: a case study of Davao, Philippines[J]. Land Economics, 1996, 72(4): 519-537.

[38] 杨卫兵, 丰景春, 张可. 农村居民水环境治理支付意愿及影响因 素研究-基于江苏省的问卷调查[J]. 中南财经政法大学学报, 2015, (4): 58-65. [Yang W B, Feng J C, Zhang K. Research on WTP and its influencing factors of rural residents' water environment management-based on questionnaire survey in Jiangsu[J]. Journal of Zhongnan University of Economics and Law, 2015, (4): $58-65$.

[39] 青岛统计信息网. 2016 年青岛市国民经济和社会发展统计公 报 [EB/OL]. (2017-03-09) [2017-12-30]. http: //www.stats- qd. gov.cn/statsqd/news/20173817355150201.shtml?typeid=990\&vid eos=. [Qingdao Statistical Information Network. Qingdao National Economic and Social Development Statistical Bulletin in 2016[EB/
OL]. (2017-03-09) [2017- 12-30]. http: //www.stats- qd.gov.cn/ statsqd/news/20173817355150201.shtml?typeid=990\&videos=. ]

[40] 山东省发展和改革委员会. 山东省“十三五”海洋经济发展规划 [EB/OL]. (2017-03-02)[2017-12-30]. http: //www.sdfgw.gov.cn/ art/2017/3/2/art_76_236838.html. [Shandong Development and Reform Commission. Planning the Development of Marine Economy in Shandong Province "in 13th Five-Year” [EB/OL]. (201703-02)[2017-12-30]. http: //www.sdfgw.gov.cn/art/2017/3/2/art_ 76_236838.html. ]

[41] 青岛政务网. “十三五”发展专题: 青岛市“十三五”蓝色经济创 新发展研究[EB/OL]. (2016-05-04)[2017-12-30]. http: //www. qingdao.gov.cn/n172/n24624151/n24625135/n24625149/n24625191/ 160504152428040155.html. [Qingdao Government Network. The "13th Five-Year” Planning: Research on the Development of the Blue Economic Innovation of Qingdao City in "13th Five- Year" [EB/OL]. (2016- 05-04) [2017- 12-30]. http: //www.qingdao.gov.cn/n172/ n24624151/n24625135/n24625149/n24625191/160504152428040155.html. ]

[42] 张志强, 徐中民, 程国栋. 条件价值评估法的发展与应用[J]. 地 球科学进展, 2003, 18(3): 454-463. [Zhang Z Q, Xu Z M, Cheng G D. The updated development and application of contingent valuation method(CVM)[J]. Advances in Earth Sciences, 2003, 18(3): 454-463. ]

[43] Arrow K J, Solow R, Portney P R, et al. Report of the NOAA panel on contingent valuation[J]. Federal Register, 1993, 58(3): 48-56.

[44] 王曦. 基于 CVM 的旅游景区农业生态资源价值研究-以龙脊梯 田为例[D]. 武汉: 华中师范大学, 2014. [Wang X. Research of Agricultural Ecology Resources Value in Tourism Scenic Spot Based on CVM-A case of Longji Terraces [D]. Wuhan: Central China Normal University, 2014. ]

[45] 杨晓兰. 基于 CVM 的金沙遗址旅游资源非使用价值评估研究 [D]. 北京: 首都师范大学, 2014. [Yang X L. Study on Non-Use Value Evaluation of Jinsha Site Tourism Resources Based on CVM [D]. Beijing: Capital Normal University, 2014. ]

[46] 雷亮, 李京梅. 浒苔对胶州湾海域休闲娱乐功能的损害评估[J] 海洋开发与管理, 2016, 33(9): 65-69. [Lei L, Li J M. An assessment of Enteromorpha's damage to Jiaozhou Bay's ecosystem service in recreation[J]. Ocean Development and Management, 2016, 33(9): 65-69. ]

[47] Venkatachalam L. The contingent valuation method: a review[J]. Environmental Impact Assessment Review, 2004, 24(1): 89-124.

[48] Mitchell R C, Cameron R T. Using Surveys to Value Public Goods: The Contingent Valuation Method[M]. Washington DC: Resources for the Future, 1989.

[49] 董雪旺, 张捷, 刘传华, 等. 条件价值法中的偏差分析及信度和 效度检验-以九寨沟游憩价值评估为例[J]. 地理学报, 2011, 66 (2): 267-278. [Dong X W, Zhang J, Liu C H, et al. Bias analysis 
and reliability and validity test in contingent valuation method: a case study of assessment of Jiuzhaigou's recreational value[J]. Acta Geographica Sinica, 2011, 66(2): 267-278. ]

[50] Freeman A M. Measurement of Environmental and Resource Values: Theory and methods[M]. Washington: Resources for the Future, 1993.

[51] Loomis J B, Walsh R G. Recreation Economic Decisions: Comparing Benefits and Costs[M]. Pennsylvania: Venture Publishing Inc., 1997.

[52] Carson R T, Flores N E, Martin K M, et al. Contingent valuation and revealed preference methodologies: comparing the estimates for quasi-public goods [J]. Land Economics, 1996, 72(1): 80-99.

[53] 徐中民, 张志强, 苏志勇, 等. 恢复额济纳旗生态系统的总经济 价值-条件估值非参数估计方法的应用[J]. 冰川冻土, 2002, 24 (2): 160-167. [Xu Z M, Zhang Z Q, Su Z Y, et al. Measuring total economic value of restoring Ejina Banner's ecosystem services-application of the non-parametric estimation[J]. Journal of Glaciology and Geocryology, 2002, 24(2): 160-167. ]

[54] 赵军, 杨凯, 邰俊, 等. 上海城市河流生态系统服务的支付意愿 [J]. 环境科学, 2005, 26(2): 5-10. [Zhao J, Yang K, Tai J, et al. Willingness to pay for ecosystem services of urban river in Shanghai[J]. Environmental Science, 2005, 26(2): 5-10. ]

[55] 张翼飞, 刘宇辉. 城市景观河流生态修复的产出研究及有效性 可靠性检验-基于上海城市内河水质改善价值评估的实证分 析 [J]. 中国地质大学学报(社会科学版), 2007, 7(2): 39-44. [Zhang L F, Liu Y H. The output research of restoring ecosystem services in urban landscape river and the validity and reliability testing: a case study of CVM applied in water quality improvement of urban river in Shanghai[J]. Journal of China University of Geosciences (Social Sciences Edition), 2007, 7(2): 39-44. ]

[56] Kriström B. Spike models in contingent valuation[J]. American Journal of Agricultural Economics, 1997, 79(3): 1013-1023.

[57] 屈小娥, 李国平. 陕北煤炭资源开发中的环境价值损失评估研 究-基于 CVM 的问卷调查与分析[J]. 干旱区资源与环境, 2012, 26(4): 73-80. [Qu X E, Li G P. The environmental value loss assessment of coal resources development in the Northern Shanxi[J]. Journal of Arid Land Resources and Environment, 2012, 26(4): 7380. ]

[58] 徐中民, 张志强, 龙爱华, 等. 额济纳旗生态系统服务恢复价值 评估方法的比较与应用[J]. 生态学报, 2003, 23(9): 1841-1850. [Xu Z M, Zhang Z Q, Long A H, et al. Comparison and application of different contingent valuation methods in measuring total economic value of restoring Ejina Banner's ecosystem services[J]. Acta Ecologica Sinica, 2003, 23(9): 1841-1850. ]

[59] 张志强, 徐中民, 龙爱华, 等. 黑河流域张掖市生态系统服务恢 复价值评估研究-连续型和离散型条件价值评估方法的比较 应用[J]. 自然资源学报, 2004, 19(2): 230-239. [Zhang Z Q, Xu Z M, Long A H, et al. Measuring the economic value of restoring ecosystem services in Zhangye city of Heihe river basin-comparison and application of continuous and discrete contingent valuation survey[J]. Journal of Natural Resources, 2004, 19(2): 230-239. ]

[60] 金建君, 王志石. 澳门改善固体废弃物管理的总经济价值评估 [J]. 中国人口·资源与环境, 2005, 15(6): 122-125. [Jin J J, Wang $\mathrm{Z} \mathrm{S}$. Economic assessment of a solid waste management program in Macao by contingent valuation method[J]. China Population, Resources and Environment, 2005, 15(6): 122-125. ] 


\title{
Evaluating the environmental value loss of coastal tourism and influencing infactors under the influence of Enteromorpha prolifera disasters at the bathing beaches in Qingdao
}

\author{
LIU Jia ${ }^{1,2}$, LIU Ning ${ }^{1}$ \\ (1. School of Management, Ocean University of China, Qingdao 266100, China; \\ 2. Main Research Base of Humanities and Social Sciences in the Ministry of Education, Marine Development \\ Studies Institute of Ocean University of China, Qingdao 266100, China)
}

\begin{abstract}
Green tide disasters have occurred frequently in Qingdao in recent years. During an outbreak of Enteromorpha prolifera, the ecological environment and landscapes of coastal tourism in Qingdao are seriously violated, and to some extent, the development of related coastal tourism activities are affected. Here, the environmental value loss of coastal tourism in Qingdao was quantitatively assessed under the influence of E. prolifera by adopting the contingent valuation method $(\mathrm{CVM})$ and investigating tourist willingness to pay for the treatment of E. prolifera (WTP). We found that tourist cognition degrees of E.prolifera were generally low. The proportion of tourists WTP and those that refused to pay for the treatment of $E$. prolifera were approximately equal. $E$ (WTP) that tourists participated in the treatment of E. prolifera disaster was $40.72 \mathrm{CNY}$, the environmental value loss of coastal tourism in Qingdao caused by E. prolifera ranged from $1212 \times 10^{6}$ $\mathrm{CNY}$ to $2136 \times 10^{6} \mathrm{CNY}$, accounting for $0.8 \%-1.5 \%$ of total tourism revenue of Qingdao city in 2016. The willingness to pay and WTP values of tourists were directly affected by the disposable income of tourists and awareness of E. prolifera. Tourist satisfaction with bathing beach had a great influence on WTP, while the degree of influence on recreational activities of coastal tourists caused by a green tide disaster and WTP values were significantly correlated.
\end{abstract}

Key words: coastal tourism; loss evaluation; contingent valuation method; Enteromorpha prolifera; Willingness to pay; Qingdao 